\title{
Short bowel syndrome: Surgical therapy
}

W DONALD BUIE, MD, OLIN G THURSTON, MD, RICHARD N FEDORAK, MD

\begin{abstract}
Many surgical solutions to short bowel syndrome have been proposed; however, none has proven to be uniformly successful. Some of these solutions, combined with optimal medical management, may represent the patient's only hope for survival without parenteral nutrition. Most forms of surgical therapy are supportive and aim at controlling three basic pathophysiological defects: decreased intestinal transit time, gastric hypersecretion, and reduced functional mucosal surface area. Conservative resection and, thus, prevention of short bowel syndrome remains the best form of treatment at present. In the future, small bowel transplantation may prove to be an important advance in therapy; however, this remains largely experimental due to continued problems with rejection. Can J Gastroenterol 1990;4(4):167-173
\end{abstract}

Key Words: Short bowel syndrome, Surgical therapy

\section{Syndrome de l'intestin court: Traitement chirurgical}

RESUME: De nombreuses solutions chirurgicales ont été proposées pour traiter le syndrome de l'intestin court mais aucune n'a remporté un succès uniforme. Certaines, combinées à un traitement médical optimal, représentent peut-être le seul espoir de survie du patient sans le recours à l'alimentation parentérale. La plupart des interventions chirurgicales apportent un traitement de soutien et visent à contrôler trois défauts physiopathologiques de base: diminution du transit intestinal, hypersécrétion gastrique et réduction de la surface fonctionnelle de la muqueuse. La résection conservatrice, c'est-à-dire la prévention du syndrome de l'intestin court, reste donc la meilleure forme de traitement pour le moment. Dans l'avenir, la transplantation du grêle sera peut-être un progrès thérapeutique important; dans une large mesure, cette intervention reste toutefois expérimentale, les problèmes de rejet continuant à se manifester. conjunction with medical therapy, and often represent the patient's only chance to become independent from parenteral nutrition.

The best form of surgical 'treatment' remains that of prevention with conservative resections (1). Even the reten-
Departments of Surgery and Medicine, University of Alberta, Edmonton, Alberta

Correspondence and reprints: Dr Richard N Fedorak, University of Alberta, Department of Medicine, Division of Gastroenterology, 519 Robert Newton Research Building, Edmonton, Alberta T6G 2C2. Telephone (403) 492-6941

Received for publication March 28, 1989. Accepted December 12, 1989 tion of a few extra centimetres of bowel can have a profound influence on the intestine's ability to adapt, and thus on the eventual prognosis. Many authors have advocated construction of multiple ostomies with a second look procedure for all marginal bowel which may be viable (1-3).

Surgical treatment can be classified into three categories based on pathophysiologic processes: slowing transit time; decreasing gastric secretions; and increasing the effective mucosal surface area (4).

\section{SLOWING INTESTINAL TRANSIT}

Surgical therapy to decrease intestinal transit time is based on the construction of a partial small bowel obstruction. Many different methods have been devised; however, all are unpredictable in their eventual effect. Most of the complications which arise from each method are due to bowel obstruction.

Antiperistaltic segments: Reversal of intestinal segments to create antiperistaltic regions was originally described by Mall in 1896 (5). He reversed variable segments of small bowel in three dogs, two of which died of bowel obstruction, while the third lived for three months. At laparotomy two months later, the segment showed retention of reversed peristalsis. Through the use of glass beads as markers, Mall also demonstrated a delay in intestinal transit time. The procedure was viewed as impossible until the 
1950s when Hammer (6) demonstrated that the duodenum could be reversed successfully resulting in an increase in intestinal transit time (6). Later in 1955, Hammer demonstrated that an $80 \%$ small bowel resection in the dog could be tolerated with the addition of a reversed ileal segment as short as 2 inches (7). In a controlled follow-up experiment, he demonstrated that dogs could survive a $90 \%$ resection for up to two years with the reversal of a small segment of intestine.

The first human report of segmental reversal was by Gibson (8) in a female with short bowel syndrome from a mesenteric infarction. She recovered following the reversal of a $7.5 \mathrm{~cm}$ segment of jejunum. Subsequently, Stahlgren (9) demonstrated that the fecal output of fat and, to a lesser degree, nitrogen, decreased with the insertion of an antiperistaltic segment in the jejunum of dogs. Using 3 to $4 \mathrm{~cm}$ paired proximal and distal reversed segments, Keller (10) proposed that the mechanism by which intestinal reversal worked was a prolongation of intestinal transit with an increase in the contact time of mucosa and luminal contents. Venables in 1966 (11) in the first human study of absorption showed a $50 \%$ decrease in fecal fat absorption with the insertion of a reversed segment.

There are two critical factors in creating antiperistaltic segments: the length of the segment and its location. If the segment is too short there will be no benefit, whereas a long segment will cause a bowel obstruction. Fink and Olson (12) favoured a $10 \mathrm{~cm}$ segment located proximally to retard gastric emptying; however, the weight of evidence is now for distal placement. Wilmore (13) failed in his attempt to treat ileostomy diarrhea over the long term with a distal $10 \mathrm{~cm}$ segment; however, there was a small short term decrease in ileostomy volume. Pertsemlidis (14) also felt that the segment should be placed as distally as possible, and used a $14 \mathrm{~cm}$ segment $12 \mathrm{~cm}$ proximal to the ostomy to prevent stagnant loop syndrome and bacterial overgrowth. Warden in 1978 (15) reported five babies with a $3 \mathrm{~cm}$ reversal placed as distally as possible, with survival in four.
In summary, intestinal reversal to create an antiperistaltic region and delay transit is one of the more common surgical interventions used in the treatment of short bowel syndrome. The ideal length in the adult seems to be 10 to $15 \mathrm{~cm}$ with placement as distally as possible. Nevertheless, inconsistent results and difficulty in predicting which patients are likely to respond have consistently dampened en. thusiasm for this approach.

Recirculating loops: The recirculating loop is an extension of intestinal reversal and was first suggested by Stafford et al in 1959 (16). Mackby in 1965 (17) showed an improved survival in dogs when a recirculating loop was combined with a separate antiperistaltic segment. Altman (18) in a controlled experiment on 20 dogs found that animals with recirculating loops had better fat absorption but lost more weight, and often died due to anorexia compared with controls. In a separate study comparing recirculating loops to segmental reversals, the latter were more often technically successful and had fewer complications (19). Although a further report of successful clinical application of the recirculating loop was submitted in 1975 , the procedure has fallen into general disfavour due to the strong evidence against its being superior to a simple reversal and to the fact that the procedure is complicated, uses long lengths of bowel and is fraught with complications causing a high mortality rate (20).

Colon interposition: Colon interposition has also been used in the treatment of short bowel syndrome. Use of the colon has three main advantages: an intrinsically slow peristalsis; decreased likelihood of causing obstruction due to the fact that colon can be placed isoperistaltically; and no requirement for the use of small bowel which is already compromised in residual length. Initially, antiperistaltic colonic segments were used and shown to be of benefit in a dog model (21). In 1967, Trinkle and Bryant (22) placed a $5 \mathrm{~cm}$ antiperistaltic segment of transverse colon in a three-week-old infant after massive resection for a mid gut volvulus. Although the patient died, she initially gained weight and had an increase in transit time with a decrease in stool frequency. Later, isoperistaltic colon interposition was investigated by Hutcher $(23,24)$. In a series of experiments with beagle puppies, he showed increased survival with the interposition of a $15 \mathrm{~cm}$ segment of isoperistaltic colon both pre-ileal and pre-jejunal after a $90 \%$ small bowel resection. The animals in both cases attained approxi. mately $70 \%$ of their expected growth with a decrease in mortality and mor. bidity compared with controls. Garcia et al (25) interposed a $24 \mathrm{~cm}$ segment of isoperistaltic colon to a $15 \mathrm{~cm}$ length of small bowel with an intact ileocecal valve in a human patient. After an adaptive period, intestinal transit time increased from 10 to $105 \mathrm{mins}$ and the patient was able to maintain adequate nutrition by oral feeding. In this patient, the development of a D-lactic acidemia was postulated to be due to bacterial overgrowth. Comparison of iso- and antiperistaltic colonic interposition was examined by Lloyd $(26,27)$ using a $90 \%$ small bowel resection in the rat. In a series of experiments, he found that antiperistaltic colonic interposition effectively prolonged transit time but had other unpredictable effects. Some animals acquired a small bowel obstruction and had, on average, lower body weights with only a slight increase in the absorption of albumin and no change in the absorption of fat compared to controls. He concluded that there was no advantage to antiperistaltic interposition over isoperistaltic and, indeed, there may be disadvantages. Further studies in dogs by Carner (28) showed that the insertion of a $20 \mathrm{~cm}$ length of antiperistaltic colon made no difference in xylose ab. sorption, $24 \mathrm{~h}$ fat excretion, bowel tran. sit time or average weight loss. Although his numbers were small, he concluded that antiperistaltic colonic interposition was of no benefit.

Glick et al in 1984 (29) published a series on six infants in which a proximal isoperistaltic segment of colon was used to treat short bowel syndrome. The seg. ments were 11 to $15 \mathrm{~cm}$ in length and three of the infants survived while the others died of sepsis and total parenteral 
nutrition-induced liver failure. His conclusions were that survival was associated with greater residual small bowel length, colon interposition at a younger age and a shorter duration of medical management. Unfortunately, the average residual bowel length in the survivors was $86 \mathrm{~cm}$ and these patients may well have adapted on their own with time. Brolin (30) published a case report of a 34-year-old female with 12 $\mathrm{cm}$ of residual length of small bowel in whom an isoperistaltic colonic interposition was done. Postoperatively, she did well in the short term; however, no nutritional studies were done.

Isoperistaltic colonic interposition is a viable alternative in the treatment of short bowel syndrome. Proximal placement seems to be best; however, the optimal length of the segment has yet to be determined. The range in the literature is from 8 to $24 \mathrm{~cm}$. All of these lengths are reported to prolong intestinal transit time. Whether or not the segment has the ability to absorb nutrients has not been established. The actual mechanism of improved absorption is presurned to be through prolonged intestinal transit time and greater mucosal contact time with luminal contents. There appear to be no short term difficulties with the procedure. In the long term, bacterial overgrowth due to stasis with resultant D-lactic acidemia and possible encephalopathy may prove to be a problem, especially in the infant population.

Experimental valves: The recognition that the presence of an ileocecal valve has a positive effect on the residual intestine's ability to adapt to resection has led to attempts to create an 'artificial' ileocecal valve. Experimental valves have been looked at as another means of slowing intestinal transit time. Intestinal valves of many different types have been used, including ablation of the outer longitudinal muscle layer $(31,32)$, the reverse intussusception valve (33), and several other valves of similar construction (34-38).

The valves have all increased transit time, but the effects have not always been predictable. Schiller (31) attempted to show that the outer muscle ablating sphincter was better than intestinal reversal in promoting survival after a $90 \%$ resection; however, his numbers were very small. Waddell (33) presented three patients with an intussusception valve: one patient having marked success, one satisfactory, and the third eventually acquiring a bowel obstruction such that the valve had to be taken down. Vinograd (36) published a study of the submucosally tunnelled valve constructed much like the re-implantation of a ureter into the bladder. He found the optimal length to be 4 to $6 \mathrm{~cm}$ in a dog model in prolonging intestinal transit time with no demonstrable reflux. Chardavoyne et al (39) examined the efficacy of a surgically created nipple valve in a dog by introducing labelled bacteria below the valve. The occurrence of bacteria above the valve was no different than with an intact ileocecal valve.

It is not surprising that clinical series examining intestinal valves are very few in number. The unpredictability, the occurrence of bowel obstruction and the loss of further intestinal length to construct the valves are all major deterrents to their routine use.

Retrograde luminal pacing: It has been known for some time that the propagation of peristalsis distally in the intestine is through electrical impulses from a pacemaker in the duodenum. Phillips et al (40), in a series of experiments in dogs, demonstrated that retrograde electrical pacing of intact jejunum enhances absorption of glucose, water and sodium. When the bowel was transsected to eliminate the proximal pacemaker, retrograde pacing had a profound effect on absorption such that it was greater than the absorption from intact jejunum with or without retrograde pacing. It appears that retrograde pacing slowed transit time and in some cases reversed the flow of luminal contents $(41,42)$. Layzell (43) later demonstrated that dogs with retrograde luminal pacing showed an increase in body weight and a decrease in fecal fat and nitrogen excretion.

Investigation into the mechanism of action has shown that the effect of pacing can be inhibited by an alphaadrenergic blockade, and thus the effect must be mediated, at least in part, by an adrenergic mechanism (44).

This therapy has remained experimental, since entrainment requires transsection of the duodenum to eliminate the intrinsic pacemaker, prolonged function of the electrodes has been difficult, and the electrodes must be implanted surgically and removed surgically when they fail.

\section{DECREASING GASTRIC HYPERSECRETION}

As mentioned previously, gastric hypersecretion has been recognized as a component of the short bowel syndrome for some time. This was felt to be detrimental for a number of reasons: there would be an increase in the volume of intestinal secretions presented to an already compromised absorptive system; the acidification of the lumen of the intestine would hinder the action of the digestive enzymes; and the resultant osmotic and volume load would further compound the fluid, electrolyte and nutrient losses already occurring in the compromised bowel.

The realization that patients with previous vagotomies and gastrectomies were more tolerant of massive resection led to the use of these procedures for the control of gastric hypersecretion in short bowel syndrome. Today, with the emergence of the $\mathrm{H}_{2}$ receptor antagonists and the realization that gastric hypersecretion is probably temporary, there is no place for the surgical treatment of gastric hypersecretion.

\section{INCREASING THE EFFECTIVE MUCOSAL SURFACE AREA}

Attempts at increasing the effective mucosal surface area has led to three completely different approaches: the growth of neomucosa; bowel lengthening and tapering procedures; and small bowel transplantation.

Neomucosa: Neomucosa was originally investigated by Cywes in 1968 (45) and Binnington in 1974 (46). They observed that the serosa of neighbouring bowel could be used as a bed to stimulate the growth of a mucosal covering. In a series of experiments on dogs and pigs, they found that if the small bowel was opened along its antimesenteric 
border and sutured to the serosa of a neighbouring piece of bowel in a longitudinal intestinal patch, the intervening serosa would be covered with a mucosa which was proven to contain enzyme levels similar to normal mucosa (46). The functional nutrient absorptive ability of this mucosa, however, was not known.

An exhaustive series of experiments by Thompson $(47-50)$ culminated in a paper in 1988 which seemed to summarize neomucosa (51). He observed that intestinal patching had an inhibitory effect on intestinal adaptation in dogs subjected to $75 \%$ intestinal resection and intestinal patching. His data showed a decrease in overall growth of the intestine and in villus height. Transit time was prolonged but the animals lost weight and had lower albumin levels. Furthermore, the increase in intestinal mucosal surface area was insignificant. It would seem that neomucosa has little if anything to offer in the treatment of short bowel syndrome at the present time.

Tapering and lengthening procedures: Intestinal tapering and lengthening procedures have met with much more success. Tapering was originally proposed when it was noted that bowel proximal to an atretic segment always became so markedly dilated that reanastomosis was difficult. Peristalsis was felt to be functionally ineffective. Initially, the antimesenteric border was opened and a longitudinal strip of bowel was removed before re-approximating the bowel. The calibre of the remaining bowel was reduced so that anastomosis was easier and peristalsis was aided due to apposition of the bowel wall during peristalsis. Patients treated in this way did indeed gain weight, and many were able to come off total parenteral nutrition (52). The major drawback to this procedure was that it necessitated the loss of valuable mucosal surface area. A modification of this technique called 'plication' (internal infolding) performed along the antimesenteric border was compared to antimesenteric excision by Ramanujan (53). He found that plicated bowel was eventually incorporated into the bowel wall and was better structurally and functionally after artificially induced bowel dilatation in a dog model.

In 1980 Bianchi (54) described in a pig model an elegant procedure called intestinal lengthening. The procedure is based on the premise that the blood supply to the small bowel runs in an alternating fashion around each side of the bowel. This allows an avascular plane to be developed between the two leaves of the mesentery such that a GIA stapler can be passed down the centre, dividing the bowel into two parallel tubes. These can be approximated endto-end in an isoperistaltic fashion to give a segment which is twice as long but only half the diameter of the original bowel. The procedure was first used clinically by Boeckman and Traylor (55) on a child with short bowel syndrome from a gastroschisis with bowel necrosis. The child was left with $39 \mathrm{~cm}$ of small bowel anastomosed to the transverse colon. This grew to a length of $50 \mathrm{~cm}$ over the ensuing years; however, the child weighed only $9.2 \mathrm{~kg}$ at four years of age. Following a Bianchi procedure, the patient required total parenteral nutrition for a further 10 weeks but was progressed to a full diet and did not require artificial nutrition after this time.

Aigrain in 1985 (56) published a report of another infant with short bowel syndrome who had an intestinal lengthening procedure done. Postoperatively, she remained on total parenteral nutrition for four weeks but was then able to progress to a regular diet. He modified the procedure to some extent by re-anastomosing the lengthened bowel in a helical formation to prevent traction on the mesenteric vessels. The problems encountered postoperatively included bacterial overgrowth proximal to the lengthened loop, nutritional intolerance and gastroesophageal reflux. Bacterial overgrowth was felt to be due to poor peristalsis in the proximal dilated duodenum which was not tapered. Oral tolerance of feeding was complete by eight months, although continuous tube feed supplementation still maintained a large proportion of the caloric intake. Urecholine was used to combat the reflux with complete success.
Thompson et al in 1985 (57) were unsuccessful in their attempt to apply the Bianchi procedure to a child with the short bowel syndrome. After dividing the bowel they re-anastomosed it, only to have one segment of the lengthened bowel become nonviable. Interestingly, the patient apparently improved clinically and the authors attributed this to the resultant tapering of the remaining segment of bowel.

A direct comparison of the efficacy of intestinal lengthening relative to other surgical treatments of short bowel syndrome has been performed in a pig model by Sigalet et al (unpublished data). They compared isoperistaltic colon interposition and intestinal lengthening. While both groups showed superior weight gain to control animals receiving no treatment, intestinal lengthening was found to be superior to isoperistaltic colon interpositioning.

Intestinal lengthening appears to be a viable alternative in the surgical treatment of short bowel syndrome. Ap. plication of this procedure seems to be tailored to the subset of the population in which the residual bowel has dilated so markedly that peristalsis is relatively ineffective (58). The advantages in. clude the fact that no mucosal surface area need be sacrificed; a slowing of transit time is obtained without causing a functional obstruction; and normal peristalsis is restored to a previously di. lated segment.

Small bowel transplantation: Successful small bowel transplantation may be the ultimate treatment for short bowel syndrome. The technical feasibility was first established experimentally in the late 1960 s by Lillihei in a dog model (59). His procedure consisted of transplanting the entire small intestine with vascular anastomosis between the respective mesenteric vessels of the graft and host. His autografts survived indefinitely, but the allografts all rejected in a matter of days. At present, the major obstacle is still rejection, as the large amount of lymphoid tissue present in the transplanted organ makes it extremely immunogenic $(60,61)$. Control of rejection can be approached by either general immunosuppression of 
the host or by alteration of the immunogenicity of the donor organ. Numerous methods of temporary control of rejection have been accomplished in the dog model using conventional host immunosuppressive therapy. Unfortunately, both azathioprine and prednisone interfere with mucosal cell replication and thus the function of the graft (60). Antilymphocyte serum alone has been shown to be insufficient in averting rejection in dogs (62).

The development of the immunosuppressive agent, cyclosporine, attracted new interest. Mono drug therapy with cyclosporine in a rat model ( $15 \mathrm{mg} / \mathrm{kg} /$ day) given for four weeks postoperatively can prevent rejection (63). Recently, low dose cyclosporine $(5 \mathrm{mg} / \mathrm{kg} /$ day $)$ given over two weeks has also prevented rejection in rats (64). Unfortunately, the results in large animal models have not been as successful. Reznick et al in 1982 (65) demonstrated that intramuscular cyclosporine $(25 \mathrm{mg} / \mathrm{kg} /$ day) would prolong survival in a transplanted dog from a mean of 12.5 to 103.8 days. The importance of parenteral administration of the drug was underlined in an extension of this work by Craddock et al (66) who demonstrated that dogs with incontinuity grafts given oral cyclosporine survived for less than one month (66). This emphasized the fact that absorptive function of an allograft is initially suboptimal, and immunosuppressive therapy should be accomplished parenterally. Further studies by Ricour (67) and Grant (68) in pigs confirm these findings. The addition of prednisone to cyclosporine therapy has been shown in dogs to improve survival over cyclosporine alone (69); however, these results have not been consistently reproduced. High dose cyclosporine therapy may not be without its own problems; a reversible impairment of intestinal absorption with a protein-losing enteropathy has been described in dogs (70). Experimental attempts at passive immune enhancement (antidonor antibody) have been entirely unsuccessful in prolonging survival (61).

Attempts at reducing the immunogenicity of the graft tissue have met with failure. Schraut (60) irradiated the graft tissue prior to transplantation in rats with no increase in graft survival. When lymph nodes from the graft were examined microscopically there was considerable lymphocyte depletion but many lymphocytes were still present. This failure to eradicate all lymph tissues may explain the lack of success. Much of the immunogenicity of the graft is felt to be due to the class II antigen-bearing cells. A new approach using pretransplant administration of monoclonal antibodies to class II antigens is being investigated. This method has already been shown to prolong graft survival of pancreatic islet transplants (71). Other approaches include pretransplant blood transfusions and segmental grafts $(72,73)$. The latter is a direct attempt to decrease the immunogenic load which, in turn, has resulted in lower cyclosporine doses necessary to prevent rejection. Another complicating factor in intestinal transplants is that one of the first functions to fail with rejection is the mucosal barrier. This enables the translocation of bacteria into the submucosa and, eventually, into the blood stream with resultant sepsis. If the rejection process proceeds to this point, it is irreversible.

Small bowel grafts contain large amounts of lymphoid tissue which creates the potential for graft versus host disease. Some authors feel that this is a laboratory phenomenon due to the heavy immunosuppression of the host immune system. Most, however, feel that rejection and graft versus host disease are not mutually exclusive and can coexist (74). Graft versus host disease can manifest itself even if rejection is prevented by cyclosporine (75). This is contrary to other organ system models in which graft versus host disease can be prevented by large doses of immunosuppressive agents. The use of antilymphocyte serum to pretreat the donor along with cyclosporine treatment to the recipient has been shown to uniformly prevent graft versus host disease in rats (76)

In addition, there remain technical problems associated with small bowel transplantation at present. Most early graft failures are due to arterial and venous thrombosis of the graft and intestinal volvulus $(65,77)$. The incidence of the latter can be decreased by ensuring proper orientation of the transplanted bowel. Monitoring the in vivo function of the graft to ensure early detection of rejection is difficult. Functional tests of water, sodium and sugar absorption with repeated small bowel biopsy have been proposed as the most reliable methods (78). A recent study by Banner et al (79) suggests that subclinical rejection can persist in the intestinal wall - in the submucosa and muscle - undetectable by mucosal biopsy alone. Additional technical problems centre around short term graft preservation. Presently, intravascular flushing with a balanced salt solution containing fructose in combination with hypothermia will provide up to $18 \mathrm{~h}$ of preservation (61). This has also been shown to decrease graft immunogenicity (80).

At present, small bowel transplantation remains an experimental alternative in the treatment of short bowel syndrome $(61,62)$. Control of rejection is still the major obstacle to successful transplants. Clinical experience with small bowel transplantation and cyclosporine therapy remains limited. Nine patients (including four children with multivisceral grafts) have undergone small bowel transplantation under cyclosporine coverage. Four have survived, although three have had their grafts removed. The remaining five have all died due to sepsis, hemorrhage or unknown causes (81).

\section{CONCLUSIONS}

Management of the short bowel syndrome continues to be a difficult clinical problem. Over the long term, the clinician depends on intrinsic adaptation of the residual intestine and this, in turn, is dependent on length, type and functional state of the residual bowel along with the presence or absence of an ileocecal valve and colon. The mechanisms of adaptation are not entirely understood, thus preventing active interventional therapy to accelerate adaptation. As the most common cause of short bowel syndrome is 
surgical resection, the best therapy is prevention using conservative resections and 'second look' procedures in the case of bowel of questionable viability. Present therapy, whether medical or surgical, is purely supportive

ACKNOWLEDGEMENTS: Dr Fedorak is the recipient of a Clinical Investigatorship from the Alberta Heritage Foundation for Medical Research. This work is supported by a grant from the Alberta Heritage Foundation for Medical Research and the Department of Surgery, University of Alberta. The authors express appreciation to Mrs Michel Pollard for her expert secretarial assistance.

\section{REFERENCES}

1. Thompson JS. Strategies for preserving intestinal length in the short bowel syndrome. Dis Colon Rectum 1987;30:208-13.

2. Grosfeld JL, Rescorla FJ. Current management of short bowel syndrome in children. J Arkansas Med Soc 1987;84:243-9.

3. Mitchell A, Watkins RM, Collin J. Surgical treatment of the short bowel syndrome. Br J Surg 1984:71:329-33.

4. Thompson JS, Rikkers LF. Surgical alternatives for the short bowel syndrome. Am J Gastroenterol 1987;82:97-106

5. Mall F. Reversal of the intestine. Hopkins Hosp Rep 1898;1:93-110.

6. Hammer JM, Visscher F, Hill EJ. Experimental gastrojejunal ulcers produced by reversing the duodenum. Arch Surg 1953;67:23-8.

7. Hammer JM, Seay PH, Johnston RL, et al. The effects of antiperistaltic bowel segments on intestinal emptying time. Arch Surg 1959;79:537-41.

8. Gibson LD, Carter R, Hinshaw DB. Segmental reversal of small intestine after massive bowel resection. JAMA 1982;182:952-4.

9. Stahlgren LH, Umana G, Roy R, Donnelly J. A study of intestinal absorption in dogs following massive small intestinal resection and insertion of an antiperistaltic segment. Ann Surg 1962:156:483-92.

10. Keller JW, Stewart WRC, Westerheide $\mathrm{R}$, Pace WG. Prolonged survival with paired reversed segment after massive intestinal resection. Arch Surg 1965;91:174-9.

11. Venables CW, Ellis H, Smith ADM. Antiperistaltic segments after massive intestinal resections. Lancet 1966:ii:1390-4.

12. Fink WJ, Olson JD. The massive bowel while the adaptive process is occurring, ing three pathophysiologic problems: decreased intestinal transit time; gastric hypersecretion; and reduced functional mucosal surface area. Initial therapy and is directed at controlling or improv-

should be medical with consideration of surgical intervention only after therapeutic failure. Patience is very important as clinical improvement due to adaptation can be expected for up to two years.

bowel syndrome. J Pediatr Surg 1981;16:994-5.

resection syndrome treatment with reversed intestinal segments. Arch Surg 1967;94:700-6.

13. Wilmore DW, Johnson CJ. Metabolic effects of small bowel syndrome. Arch Surg 1968;97:784-91.

14. Pertsemlidis D, Kark AE. Antiperistaltic segments for the treatment of short bowel syndrome. Am J Gastroenterol 1974:62:526-30.

15. Warden KJ, Wesley JR. Small bowel reversal procedure for treatment of the 'short gut' baby. J Pediatr Surg 1978;13:321-3.

16. Stafford ES, Schnaufer L, Cone DF. The isolated circular intestinal loop. Bull Johns Hopkins Hosp 1959;104:260-1.

17. Mackby MJ, Richards V, Gillfillan RS, Floridia R. Methods of increasing the efficiency of residual small bowel segments. Am J Surg 1965;109:32-8.

18. Altman DP, Ellison EH. Massive intestinal resection: Inadequacies of the recirculating loop. Surg Forum 1965;16:365-7.

19. Budding J, Smith CC. Role of recirculating loops in the management of massive resection of the small intestine. Surg Gynecol Obstet 1967;125:243-9.

20. Camproden R, Guerrero JA, Salva JA, Jornet J. Shortened small bowel syndrome: Mackby's operation. Am J Surg 1975;129:585-6.

21. Vayve P, Hureau J, Soyer R. Use of antiperistaltic colon segment interposition on lower small bowel motility following extensive resection. Ann Chir 1967;21:521-6.

22. Trinkle JK, Bryant LR. Reversed colon segment in an infant with small bowel resection: A case report. J Ky Med Assoc 1967;65:1090-1.

23. Hutcher NE, Salzberg AM. Pre-ileal transposition of colon to prevent the development of short bowel syndrome in puppies with 90 percent small intestinal resection. Surgery 1971;70:189-97.

24. Hutcher NE, Mendez-Picon C, Salzberg AM. Prejejunal transposition of colon to prevent the development of short bowel syndrome in puppies with 90 percent small intestine resection. J Pediatr Surg 1973;8:771-7.

25. Garcia VF, Templeton JM, Eichelberger MR, Koop CE, Vinograd I. Colon interposition for the short
26. Lloyd DA. Colonic interposition between the jejunum and ileum after massive small bowel resection in rats. Prog Pediatr Surg 1978;12:51-106.

27. Lloyd DA. Antiperistaltic colonic interposition following massive small bowel resection in rats. J Pediatr Surg 1981;16:64-9.

28. Carner DV, Raju S. Failure of antiperistaltic colon interposition to ameliorate short bowel syndrome. Am Surg 1981;47:538-40.

29. Glick PL, De Lorimier AA, Adzick NS, Harrison MR. Colon interposition: An adjuvant operation for short gut syndrome. J Pediatr Surg 1984;19:719-25.

30. Brolin RE. Colon interposition for extreme short bowel syndrome: A case report. Surgery 1986;100:576-80.

31. Schiller WR, DiDio LJA, Anderson MC Production of artificial sphincters: Ablation of the longitudinal layer of the intestine. Arch Surg 1967;95:436-41.

32. Lopez-Perez GA, Martinez AJ, Machuca J, et al. Experimental antireflux intestinal valve. Am J Surg 1981;141:597-600.

33. Waddell WR, Kern F, Halgrimson CG, Woodbury JJ. A simple jejunocolic valve for relief of rapid transit and the short bowel syndrome. Arch Surg 1970;100:438-44.

34. Ricotta J, Zuidema GD, Gadacz RT, Sadri D. Construction of an ileocecal valve and its role in massive resection of the small intestine. Surg Gynecol Obstet 1981;152:310-4.

35. Careskey J, Weber TR, Grosfield JL. lleocecal valve replacement: Its effect on transit time survival and weight change after massive intestinal resec. tion. Arch Surg 1981;116:618-22.

36. Vinograd I, Merguerian P, Udassin R, Mogle P, Nissan S. An experimental model of a submucosally tunnelled valve for the replacement of the ileo-cecal valve. J Pediatr Surg 1984;19:726-31

37. Stacchini A, DiDio LJ, Primo ML, et al. Artificial sphincter as a surgical treatment of experimental massive resection of the small intestine. Surg Forum 1970;21:310-2.

38. Sawchuk A, Goto S, Yount J, et al. Chemically induced bowel denervation improves survival in short bowel 
syndrome. J Pediatr Surg 1987;22:4926.

39. Chardavoyne R, Isenberg H, Tindel M, Stein T, Wise L. Efficacy of a surgically constructed nipple valve following massive small bowel resection. Gastroenterology 1983;84:1122. (Abst)

40. Collin J, Kelly KA, Phillips SF. Enhancement of absorption from the intact and transsected canine small intestine by electrical pacing. Gastroenterology 1979;76:1422-8.

41. Gladen HE, Kelly KA. Electrical pacing for the short bowel syndrome. Surg Gynecol Obstet 1981;153:697-700.

42. Sawchuk A, Nogami W, Goto S, et al. Reverse electrical pacing improves intestinal absorption and transit time. Surgery 1986;100:454-60.

43. Layzell T, Collin J. Retrograde electrical pacing of the small intestine: $A$ new treatment for short bowel syndrome? Br J Surg 1981;68:711-3.

44. Bjorck S, Phillips SF, Kelly KA. Mechanisms of enhanced intestinal ab. sorption with electrical pacing. Gastroenterology 1984;86:1029. (Abst)

45. Cywes S. The surgical management of massive bowel resection. J Pediatr Surg 1968;3:740-8.

46. Binnington NB, Tumbleson ME, Ternberg JL. Use of jejunal neomucosa in the treatment of the short gut syndrome in pigs. J Pediatr Surg 1975;10:617-21.

47. Thompson JS, Vanderhoof JA, Antonson DL, Newland JR, Hodgson PE. Comparison of techniques for growing small bowel neomucosa. J Pediatr Surg 1984:36:401-6.

48. Thompson JS, Kampfe PW, Newland JR, Vanderhoof JA. Growth of intestinal neomucosa on prosthetic materials. J Surg Res 1986:41:484-92.

49. Thompson JS. Growth of neomucosa after intestinal resection. Arch Surg 1987;122:316-9.

50. Thompson JS, Hollingsed TC, Saxena SK. Prevention of contraction of patched intestinal defects. Arch Surg 1988;123:428-30.

51. Thompson JS, Harty RJ, Saigh JA, et al. Morphologic and nutritional responses to intestinal patching follow. ing intestinal resection. Surgery 1988;103:79-86.

52. Weber TR, Vane DW, Grosfield JL. Tapering enteroplasty in infants with bowel atresia and short gut. Arch Surg 1982;117:684-8.

53. Ramanujan TM. Functional capabilities of blind small loops after intestinal remodeling techniques. Aust N Z J Surg 1984;54:145-50.
54. Bianchi A. Intestinal loop lengthening: A technique for increasing small intestinal length. J Pediatr Surg 1980;15:145-51.

55. Boeckman CR, Traylor R. Bowel lengthening for short gut syndrome. J Pediatr Surg 1981;16:996-7.

56. Aigrain Y, Cornet D, Cezard JP, Boureau M. Longitudinal division of small intestine: A surgical possibility for children with the very short bowel syndrome. Z Kinderchir 1985;40:233-6.

57. Thompson JS, Vanderhoof JA, Antonson DL. Intestinal tapering and lengthening for the short bowel syndrome. J Pediatr Gastroenterol Nutr 1985;4:495-7.

58. Bianchi A. Intestinal lengthening: An experimental and clinical review. J R Soc Med 1984;77:35-41.

59. Lillehei RL, Idezuki Y, Feemster JA, et al. Transplantation of stomach, intestine and pancreas: Experimental and clinical observations. Surgery 1967:62:721-41.

60. Schraut WH. Current status of small bowel transplantation. Gastroenterology 1988;94:525-38.

61. Pritchard TJ, Kirkman RL. Small bowel transplantation. World J Surg 1985;9:860-7.

62. Quint J, Hardy MA, State D. Effects of antilymphocyte serum on absorptive function and survival of dog intestinal allograft. Surg Forum 1968;19:184-6.

63. Shimazu MR, Grogan JB, Raju S. Long term survival of orthotopic bowel allografts in the rat treated with short term low dose cyclosporine. Transplantation 1988;46:673-7.

64. Reznick RK, Craddock GN, Langer B, Giles T, Aillen JB. Structure and function of small bowel allografts in the dog: Immunosuppression with cyclosporine A. Can J Surg 1982;25:51-5.

65. Craddock GN, Nordgren SR, Reznick RK, et al. Small bowel transplantation in the dog using cyclosporine. Transplantation 1983;35:284-8.

66. Ricour C, Revillon Y, Annaud Battandier F, et al. Successful small bowel allografts in piglets using cyclosporine. Transplant Proc 1983;15:3019-26.

67. Grant D, Duff J, Zhong R, et al. Successful intestinal transplantation in pigs treated with cyclosporine. Transplantation 1988;45:279-84.

68. Fujiwara H, Grogan JB, Raju S. Total orthotopic small bowel transplantation with cyclosporine. Transplantation 1987;44:469-74.

69. Collin J, Dennison AR, Watkins RM, Millard PR, Morris PJ. Segmental small intestinal allografts. II. Inadequate function with cyclosporine immunosup. pression evidence of a protein-losing enteropathy. Transplantation 1987;44:479-83.

70. Lloyd DM, Gaber AO, Buckingham M, Stuart FP, Thistlewaite JR. Prolonged survival of rat pancreas allografts by ex vivo perfusion with monoclonal antibodies specific for class II major histocompatibility antigens. Surg Forum 1987;38:375-7.

71. Martinelli GP, Knight RK, Kaplan S, Racelis D, Dikman SH, Schanzer H. Small bowel transplantation in the rat. Effect of pretransplant bowel transfusions and cyclosporine on host survival. Transplantation 1988;45:1021-6.

72. Kimura K, Money SR, Jaffe BM. Short segment orthotopic intestine isografts and allografts in enterectomized rats. Transplantation 1987;44:579-82.

73. Fujiwara H, Raju S, Grogan JB, Levin JR, Johnson WW. Total orthotopic small bowel allotransplantation in the dog. Features of atypical rejection and graft versus host reaction. Transplantation 1987;44:747-53.

74. Diflo T, Maki T, Balogh K, Monaco AP. Graft versus host disease in fully allogenic small bowel transplantation in the rat. Transplantation 1989;47:7-11.

75. Lee KKW, Schrant WH. In vitro allograft irradiation prevents graft versus host in small bowel transplantation. J Surg Res 1985;38:364-72.

76. Kirkman RL. Small bowel transplantation. Transplantation. 1984;37:429-37.

77. Dennison AR, Collin J, Watkins RM, Millard PR, Morris PJ. Segmental small intestinal allografts in the dog. I. Morphological and functional indices of rejection. Transplantation 1987;44:474-8.

78. Banner B, Dean P, Williams J. Morphologic features of rejection in long surviving canine small bowel transplants. Transplantation 1988;46:665-9.

79. Raju S, Fujiiura H, Levin JR, Grogan JB. Twelve hour and twenty-four hour preservation of small bowel allografts by simple hypothermia. Survival utilizing cyclosporine. Transplantation 1988;45:290-3.

80. Cohen Z, Wassef R, Langer B. Transplantation of the small intestine. Surg Clin North Am 1986;66:583-8.

81. Grant DR. Transplantation of the small intestine: Current status. XIIth International Congress of the Transplantation Society. Sydney, Australia, August 14-19, 1988. (Abst) 


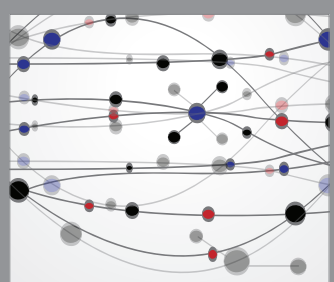

The Scientific World Journal
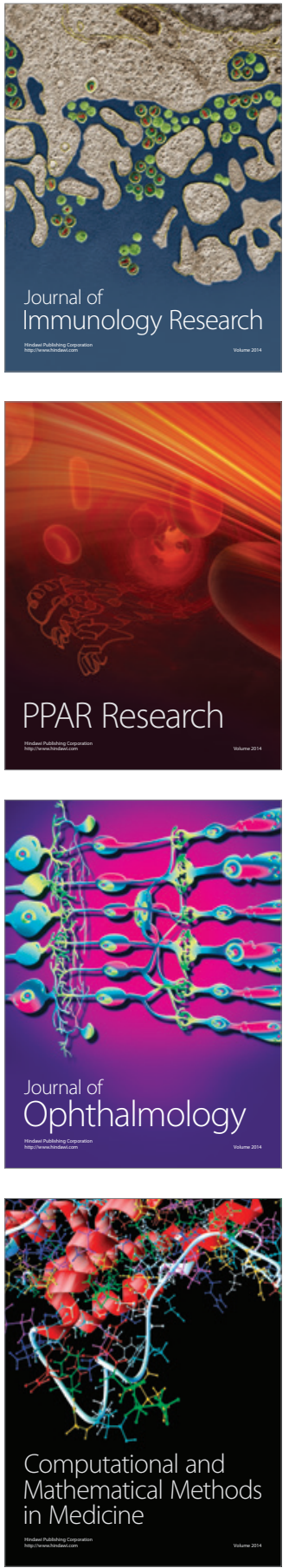

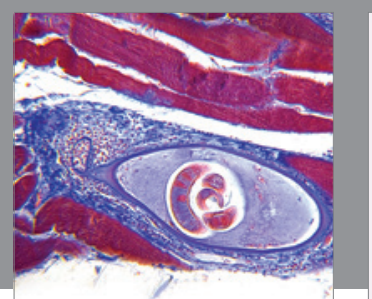

Gastroenterology Research and Practice

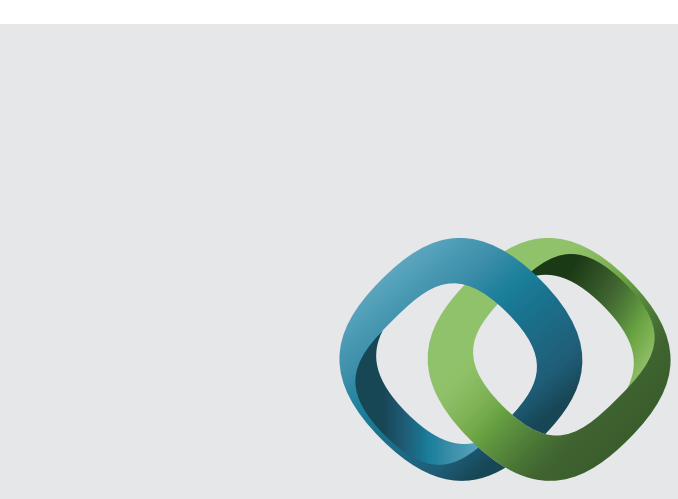

\section{Hindawi}

Submit your manuscripts at

http://www.hindawi.com
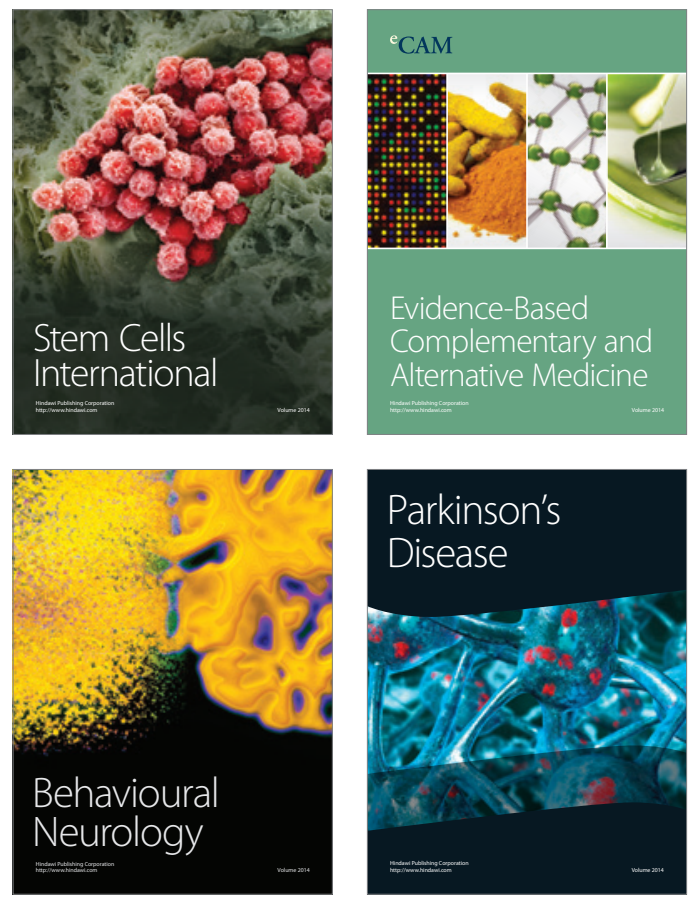
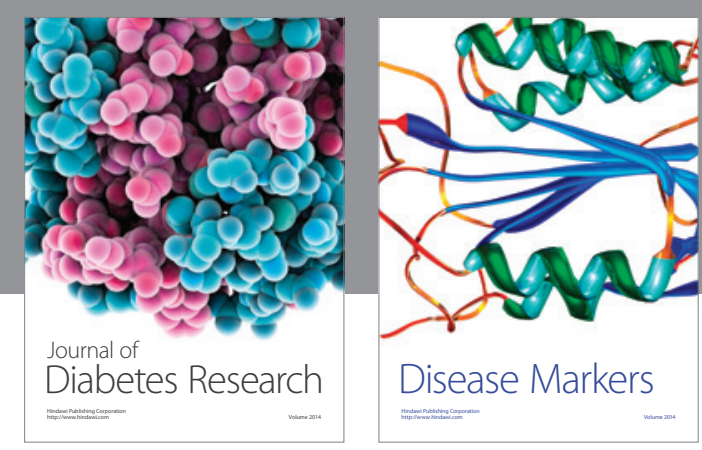

Disease Markers
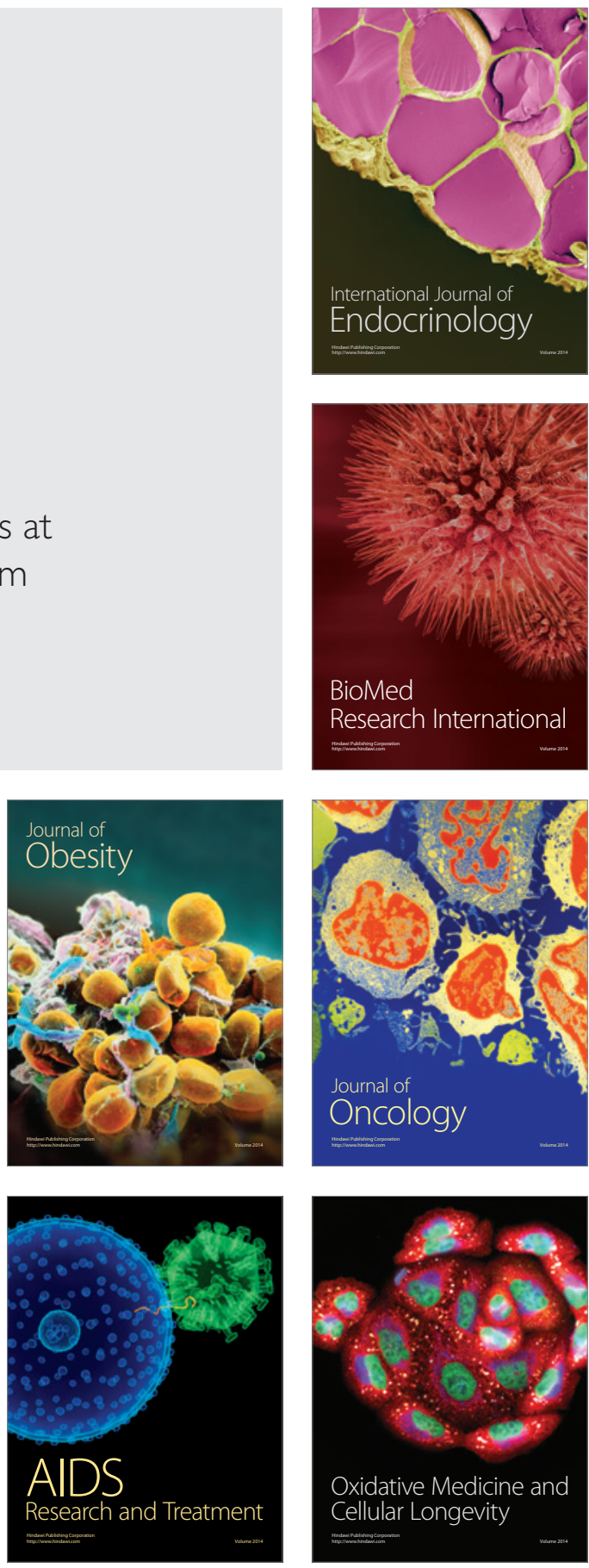